\title{
Tooma rõõmusõnumid
}

Thomas Salumets, „Unforced Flourishing: Understanding Jaan Kaplinski“ (Montreal \& Kingston - London - Ithaca: McGill-Queen's University Press, 2014)

Thomas Salumets, „Mõju mõnu“. (Studia litteraria Estonica 14.) Koostajad Thomas Salumets ja Arne Merilai. Tõlkijad Vahur Aabrams, Kairit Kaur, Arne Merilai, Maarja Pärtna, Ene-Reet Soovik, Liina Sumberg, Mari Tarvas, Urmas Tõnisson, Kadri Tüür, Märt Väljataga. Toimetajad Arne Merilai ja Ele Süvalep. Kaanekujundjaja Kalle Paalits. (Tartu: Tartu Ülikooli Kirjastus, 2014)

\section{Arne Merilai}

Eelmine, 2014. aasta oli Vancouveris elavale-töötavale kirjandusteadlasele Thomas Salumetsale tulemusrikas: tema sulest ilmus kaks monograafiat - ingliskeelne biograafia Jaan Kaplinskist ja emakeelne tõlkeline artiklikogumik. Kauaoodatud rõõmusõnum nii põhjalikule autorile endale, tema sõbrale-paleusele Vana-Jaanile kui ka meile lugejaile kodu- ja välismaal.

Thomas Salumets sündis 1956. aastal Saksamaal, Emajõe lahingus osalenud ja raskelt haavata saanud rindemehe perekonnas. Gümnaasiumi lõpetas ta Heidelbergis, germanistika bakalaureuseõppe summa cum laude Toronto Ülikoolis Kanadas (1976-1980). Magistriksdoktoriks haris ta end aga Princetoni Ülikoolis USAs (1980-1985), kus kaitses doktoriväitekirja „Zur Interpretation und Edition der Werke F. M. Klingers“. Alustanud õppejõuna LääneOntario ja Toronto ülikoolides, töötab professor 1987. aastast alates Briti Columbia Ülikoolis (BCU) Vancouveris, Kanadas. 1992. aastal omistati talle tenuur ja Euroopast Alexander von Humboldti Fondi prestiižne, eluaegsete privileegidega stipendium. Salumets on juhatanud BCU võrdleva kirjandusteaduse õppetooli ja germanistikaosakonda, aastatel 2006-2011 oli ta sama ülikooli Kesk-, Ida- ja Põhja-Euroopa osakonna juhataja. Ta on olnud nii Baltiuuringute organisatsiooni Association for the Advancement of Baltic Studies (AABS) president (2002-2006) ja kauaaegne nõukogu liige kui ka ajakirja Journal of Baltic Studies peatoimetaja (1998-2001) ning nõuandja. Arusaadav, et nõutava eksperdina on ta veel väga mitme akadeemilise ühenduse liige.

Thomas Salumets kogus tuntust oma süvenemisega Norbert Eliase filosoofiasse. Selle tulemusena avaldas ta artiklikogumiku "Norbert Elias and Human Interdependencies“ (Montreal: McGill-Queen's University Press, 2001, e-raamat 2009), mis on leidnud head vastuvõttu. Eliase „figuratsioonilise sotsioloogiaga“ saame tutvuda ka eesti keeles, Salumetsa 
saatesõnaga varustatud kaheköitelise „Tsiviliseerumisprotsessi“ kaudu (2005); kuid autorit tutvustas ta meile ajakirjas Keel ja Kirjandus juba 1999. aastal. ${ }^{1}$

Friedrich Maximilian von Klingeri kogutud teoste väljaandmise kureerimist koos Sander L. Gilmaniga peab Salumets oma teadustegevuse oluliseks teetähiseks. Selle kõrval on ta käsitlenud mahukalt teisigi Liivi- ja Eestimaaga seotud tormi ja tungi autoreid, eriti Jakob Michael Reinhold Lenzi loomingut. Nii oma õppetöös kui kirjasõnas tutvustab ta sageli ka eesti kirjandust ja kultuuri: Jaan Kross, Viivi Luik, Tõnu Õnnepalu, Uku Masing, Sofi Oksanen, Veljo Tormis. Laiemalt käsitleb ta kogu Läänemere ja Balti konteksti rõhuga germaani ja soome-ugri keeltel: Tomas Tranströmer, Henning Mankell, Elias Lönnrot, Günter Grass, Johannes Bobrowski, Aleksandr Solženitsõn, laulev revolutsioon...

Professor Salumetsa isiklikud ja akadeemilised kokkupuuted Eestiga on tihedad. Ta suhtleb valitud sõpradega, nagu Jaan Kaplinski, Tiia Toomet või Jüri Talvet; Saksamaalt asus Saaremaale elama tema vanem õde, samuti nüüdseks kahjuks juba lahkunud vanemad. Erialaliselt vajatakse sageli tema nõu väitekirjade, kandidatuuride ja granditaotluste oponendiretsensendina. Eesti taasiseseisvumisest alates on ta üles astunud ka konverentsidel Tartus ja Tallinnas, teemadeks Lenz, Klinger, Elias, Kross, Kaplinski, Masing, ökokriitika... Juba tosin aastat tagasi andis kirjastus IImamaa välja Salumetsa koostatud ja saatesõnastatud Jaan Kaplinski mõttelookogumiku „Kõik on ime“ (2004), mille üheks tuummõisteks on rahvuse enesekolonisatsioon.

\section{„Unforced Flourishing: Understanding Jaan Kaplinski“ (2014)}

Salumetsa süvitsiminev psühhologiseeriv biograafia tutvustab maailmale lähemalt rahvusvaheliselt tuntud eesti intellektuaali tundemaailma, mõttesüsteemi, kujunemislugu. Mõne aja pärast saame käsitlust loodetavasti ka oma emakeeles lugeda, Kersti Undi tõlgituna ja kirjastuse Varrak üllitatuna.

Monograafia tagakaanel arvab Washingtoni Ülikooli Baltica-õppejõud Guntis Šmidchens, et tegemist on olulise panusega maailmakirjanduse uurimisse: Salumetsa arutelud kaplinskilikust teisitimõtlemisest, luuletaja suhtest võimu või avaliku arvamusega on värsked ja valgustavad. Luuletaja-tõlkija Harvey L. Hix, Wyomingi ülikooli professor USAst, kiidab sealsamas, kuidas Eesti kultuuriheerose mõistmine on viidud täiesti uuele tasemele nii sügavuste loodimise kui ka tähendusliku detailirikkuse mõttes: selgitav ja ärgitav lugemine Balti ajaloo, poliitika, kultuuri huvilisele või kellele tahes.

Nagu suur pealkiri ütleb, näeb autor sundimatu kasvamise tajus ja idees kaplinskiliku elutunnetuse olemust: selle kujundi mantra läbib köite kõiki lehekülgi. Raamatu sissejuhatus kannab pealkirja „Tartust Calgary olümpiale“ („From Tartu to the Calgary Olympics“), millele

1 Artiklis „Luule ja humanitaarteadused: teine Norbert Elias“, vt Keel ja Kirjandus, nr 7, Ik 466-479. 
järgnevad peatükid „Rahutu mõttetark“ („Troubled Sage“), „Ära puutu seda kivi, Sisyphos“ („Don't Touch that Rock, Sisyphus“), „Meedium ei ole sõnum“ („The Medium Is Not the Message“), „Keha signaalid“ („Body Signals“), „Sõltuvusiha“ („Desire for Dependence“), „Teisel pool teisitimõtlemist“ („Beyond Dissidence“), „Enesekolonisatsioon“ („Selfcolonization“), „Vaba õitsemise kunst“ („The Art of Unforced Flourishing“).

Autori empaatiavõime nii uuritava kui ka tema ajastu hinge sisseelamisel on ühtaegu imeteldav ja raputav. Salumets mõistab olla samavõrd delikaatne kui ka psühhoanalüütiliselt teravapilguline, mis eriti kontrastselt ilmneb kehamärkide alapeatükkides nagu „Armuvalus - kiindumusest ahistuseni“ („Love sick - from affection to affliction“), „Seksuaaltrauma kontrolli kadumine“ („Sexual trauma - losing control“) või, jällegi, ajamärkide hämmastavalt usaldusväärsel taastamisel: „40 kiri - keisri hullud“ ("The letter of 40 - the czar's madmen“). Lugedes võisin vahel isegi ehmuda, kas käsiteldav ise ei saa äkki mõnest kohast lausa vapustust (mis olevatki tagantjärele kinnitust leidnud)... Kuid loomulikult pääseb võidule teadmine, et Sokratesest armsamgi on ikka tõde ise, sest ega muul ole ausalt öeldes mõtet. Igaüks maadleb lõppeks oma psüühikaga, selle geniaalsuse või arengupeetusega, teiste või iseenda kiituste ja laitustega, seega milles probleem. Kõige eeldatava kõrval - Uku Masing, budism, sotsio- ja ökokriitika, väikerahvus ja globalism, assotsiatiivne vabavärss, uhke üksindus toetub Salumets Kaplinski luule tõlgendamisel sügavuti tema regivärsikeele ja -meele lembusele, elusale ürgseosele. Tavapärast kronoloogilist-refereerivat ülevaadet Kaplinski luule-, proosa- ja esseeraamatutest sellest köitest me nõnda ei leia: Salumetsa huvid on algustes ja olemustes, loomuliku kasvu - vaba loomise - avaldustes.

Küllap võib väita, et Kaplinski perekonna kõrval tunneb Salumets teda kui inimest ja autorit kogu maailmas kõikse paremini. Kindlasti ei ole põhjus ainult selles, et ainsana siin ilmas on talle kasutada antud luuletaja erapäevikud. Nii suur usaldus ei teki üleöö, vaid pikkade aastate jooksul ja põhjusega. Seda suuremat respekti lugedes tajume, kuivõrd paljugi tundub olevat ka ütlemata jäänud. Seda aga mitte olulise varjamiseks, vaid pigem kaasaloomist virgutava delikaatse, tagasihoidva stiili tõttu: isetäituvad mõttelüngad. Salumets ei ole oma objekti hõivaja, vaid ainult esiletooja ja toetaja, seega loomult fenomenoloog. Uurijana on talle esmane sisu, representatsioon, mitte isiklik retoorika, presentatsioon. Kuid enesetaandus ja esituse teisesus ei tähenda kaugeltki poeetika puudumist. Vastupidi, monograafia stiil on elegantne, selles valdab kõrgstiililähedane meelerahu, mida on nauditav jälgida. Kirgas mõtteselgus, vaimne siredus - serenity. Kaplinski suhtes näib see ainuvõimalikult adekvaatne. Raske on kergeks saada, aga siiski saadakse.

Biograafi eesmärk näib olevat tabada läbi aegade voolanud subjektiivsust, mõista ja sõnastada selle elujõudu. Mida paremini me suudame vaigistada oma ego müra, seda rohkem võime end päriselt usaldama hakata. Salumetsa sisendusjõuline Kaplinski pakub maailmale inimarengu haruldast sihti: mida vähem sekkuda, seda rohkem saame õitseda. Kuidas saavutada vaikiv, tähelepanelik, spontaanne seos millegi iseenesest looduvaga, mitte kunstlikult 
tehtuga? Kuidas saab tänapäeval mitte kalkuleerida? Kuidas saavutada sõnatu suhtlus ja inimlik lähedus, looduslik rikkus? Suurim oht inimliku täiuse teel on omaenda loomulikkusest võõrdunud inimene ise.

McGill-Queen'si ülikooli kirjastuse raamatublogis on Salumets teinud Kaplinskiga post factum lühiintervjuu, mida too arvab monograafia peatsest tõlkimisest eesti keelde. ${ }^{2}$

Kirjanik vastab, et ta ei soovi kinni jääda ühessegi kesta, muutuda iseenda või teiste epigooniks, kus kaob side elu voolamise ja imega. Ta pelgab pisut, kas inimesed mõistavad teda iseseisva intellektuaalina, kel koduks kirjasõna vabariik, La République internationale des lettres, sest ta ei taha olla ainuüksi eesti intellektuaal. Võib juhtuda, et mõni lugeja paneb pahaks autori intiimelu ausat kirjeldamist, kuid küllap on käes aeg harjuda juba selliste raamatutega: ka autorid on inimolendid oma tugevuste ja nõrkustega ja vahest mõistetakse kirjanikuks olemist isegi paremini, kui nähakse, et enamik neist ei olegi üliinimlikud geeniused ega dekadentlikud boheemlased. Kuivõrd Kaplinski arvates puudub tal õnneks rahvusliku kangelase või pühaku aura, siis vististi ei šokeeri see teos siiski eesti lugejat üleliia. Mis puutub aga suhetesse idapoolse võimuga, siis Kaplinski meelest ei ole tema hoiakud oluliselt muutunud: ta arvab tegelikult Venemaast ja selle poliitikast enam-vähem sedasama, nagu Henry Kissinger, Jack Matlock või kadunud George Kennan. Vene liider tunneb alandust Lääne suhtumise pärast, näeb NATO ittalaienemises ähvardust ja reageerib sellele. Aga mõnikord reageeritakse seal üle, nagu omakorda USAs.

\section{Thomas Salumetsa tõlkeartiklite valimik „Mõju mõnu“ (2014)}

Kogumik tutvustab Kaplinski-teema kõrval veel mitmest aspektist seda väärt meest Vancouverist - meie akadeemilist kaasautorit, retsensenti-oponenti, kel eesti ja maailma kultuur südamel. Autori bibliograafia ja nimeregistriga varustatud kogumik sisaldab kakskümmend kolm käsitlust, millest neliteist on tõlkinud selle raamatu tarbeks Vahur Aabrams, Ene-Reet Soovik, Kadri Tüür, Kairit Kaur ja Maarja Pärtna. Raamatu üheksa artiklit ilmusid algselt saksa keeles, ülejäänud olid ingliskeelsed. Salumetsa hõlmatav periood ulatub üle kahe sajandi, alates Prantsuse revolutsiooni poolt mõjutatud saksakeelsest tormist ja tungist kuni tänapäeva eesti kirjanduseni välja.

„Mõju mõnul“ on kuus alaosa. Sissejuhatavas jaos vaagib autor humanitaarteaduste olevikku ja tulevikku ning avardab dialoogi Morgensternist Mihkelsonini Eneken Laanese väitekirja analüüsides. Teine tsükkel, „Väärikalt väljaspool“, käsitleb iseloomulikult selliseid „tõrksaid“ autoreid nagu nobelist Grass, Klinger, Kaplinski, Elias. „Mõju mõnud“ (parafraas mõjuängist) vaatleb Goethet, Harold Bloomi, Eliast, Kaplinskit ja Masingut. „Võimuta võim“ koondab vaatlusi Marie von Ebner-Eschenbachi, Klingeri, Friedrich Schilleri ja Lenzi ajapoliitilistest proosast ja draamast, Prantsuse revolutsiooni sotsiogeneesist ning tormi ja tungi

2 Vt http://www.mqup.ca/blog/qa-thomas-salumets-jaan-kaplinski/ (29.05.2015). 
poeetikast. „Ränded“ on pühendatud „põgenemiskunstnikele“ ehk välis- või sisepagulusele, teemadeks on Klingeri tegevus Tartu ülikooli kuraatorina, ülemaailmne germanistika, kaplinskilikult nähtud postkolonialism või vabaduse- ja kodutunne Krossi, Kaplinski ning looduslähedase kanadalanna K. Linda Kivi loomingus. Raamatu viimane sektor kannab pealkirja "Kirjanduse seltsis“, kus arutlusaineks on „teine Elias“, rahvusvahelise komparativismi olukord, Kross ja rahvuslus ning milleks Faustile „Faust“.

Nimeregister ilmutab, et lisaks ülalnimetatutele seob Salumets argumente teistest sagedamini selliste nimedega nagu Max Rieger, Richard Rorty, Aleksander I, William Shakespeare, Wolfgang Welsch, Milan Kundera, Václav Havel, Thomas McFarland, Friedrich Nietzsche, Johann Gottfried Herder, Georg Nicolovius, Andreas Huyssen, Christoph Hering, Immanuel Kant, Wolfgang Amadeus Mozart, Jochen Schmidt, Georg Parrot, Hans-Gerd Winter, Christoph Wieland, Charles Taylor, Walter Hinderer, Fritz Martini, Olga Smoljan, Edward Said, Michael Schröter, Francesco Loriggio, Jean-Jacques Rousseau... Sellest loetelust saab ehk aimu uurija mahukast kataloogist, kuigi viimasel ajal on Kaplinski kõrvale kerkinud juba uus kiht korduvaid viited, nagu Takeo Doi, Arne Næss, Arvo Pärt, John Cage, Gerhard Richter, Gary Snyder... Paistab, et järgmise raamatu teemaks on kujunemas midagi schweitzerlikku: aukartus lihtsuse ees.

Salumets ei uduta, spekuleeri ega lange paatosesse, vaid on põhjalik, detailne, kontekstuaalselt seosterikas ja perfektsionistlikult täpne - usaldusväärne eeskuju igale kirjandusteadlasele. Nagu ütleb oma pikemas saatesõnas akadeemik Marketa Goetz-Stankiewicz, on Salumets sõltumatu, kuid samas malbe ja diskreetne. Ta argumenteerib põhjalikult ja üldistab kaugele, kuid ei ole kunagi pealetükkiv. „Mõju mõnu“ eessõna lõpeb tõdemusega (Ik 14): „[m]ida tähelepanelikumalt me tema esseid loeme, seda rohkem saab selgeks, et vaatamata suurele erinevusele sisaldavad nad peidetud ühtsust - ja see on haruldane nähtus meie väliselt „globaliseeritud”, kuid sisemiselt killustunud maailmas“.

Thomas Salumets on aus mees, kes peab lubadusi ega võltsi ajalugu. 29. mail 2015 valiti ta Tartu Ülikooli audoktoriks.

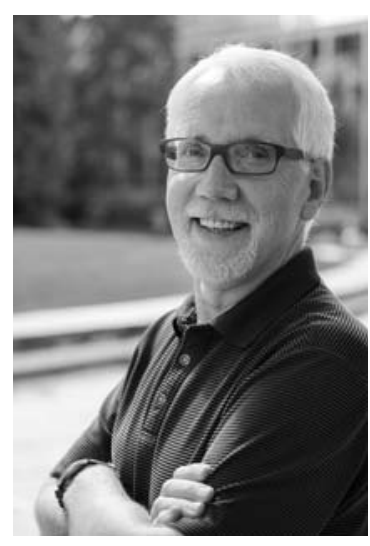

Thomas Salumets.

Foto autor: Varun Saran 